\title{
Relationship of home blood pressure with target-organ damage in children and adolescents
}

\author{
George S Stergiou ${ }^{1}$, Periklis P Giovas ${ }^{1}$, Anastasios Kollias ${ }^{1}$, Vayia C Rarra ${ }^{1}$, John Papagiannis ${ }^{2}$, \\ Dimitris Georgakopoulos ${ }^{3}$ and Andriani Vazeou ${ }^{4}$
}

The objective of this study was to compare home blood pressure (HBP) vs. ambulatory (ABP) and clinic (CBP) measurements in terms of their association with target-organ damage in children and adolescents. A total of 81 children and adolescents (mean age $13 \pm 3$ years, 53 boys) referred for elevated CBP had measurements of CBP ( 1 visit), HBP (6 days) and ABP (24-h). Seventy-six participants were also assessed with carotid-femoral pulse wave velocity (PWV) and 54 with echocardiography. Average CBP was $122.1 \pm 15.1 / 71 \pm 12.9 \mathrm{~mm} \mathrm{Hg}$ (systolic/diastolic), HBP $121.3 \pm 11.5 / 69.4 \pm 6.6 \mathrm{~mm} \mathrm{Hg}$ and $24-\mathrm{h} \mathrm{ABP} 118.9 \pm 12 /$ $66.6 \pm 6.1 \mathrm{~mm} \mathrm{Hg}$. Left ventricular mass (LVM) was correlated with systolic blood pressure (BP) (coefficient $\mathrm{r}=0.55 / 0.54 / 0.45$ for 24-h/daytime/nighttime ABP, 0.53 for $\mathrm{HBP}$ and 0.41 for CBP; all $P<0.01$ ). No significant correlations were found for diastolic BP. PWV was also significantly correlated with systolic BP ( $r=0.52 / 0.50 / 0.48$ for $24-h /$ daytime/nighttime ABP, 0.50 for HBP and 0.47 for CBP; all $P<0.01$ ). Only diastolic ABP and HBP were significantly correlated with PWV ( $r=0.30$ and 0.28 , respectively, $\boldsymbol{P}<0.05$ ). In multivariate stepwise regression analysis (with age, gender, body mass index [BMI], clinic, home and 24-h ambulatory systolic/diastolic BP and pulse pressure, clinic, home and 24-h heart rate as independent variables), PWV was best predicted by systolic HBP $\left(R^{2}=0.22\right.$, beta \pm s.e. $\left.=0.06 \pm 0.01\right)$, whereas LVM was determined $\left(R^{2}=0.67\right)$ by $24-\mathrm{h}$ pulse pressure (beta $=1.21 \pm 0.41$ ), age (beta $=2.93 \pm 1.32$ ), 24-h heart rate (beta $=-1.27 \pm 0.41$ ) and BMI (beta $=1.78 \pm 0.70$ ). These data suggest that, in children and adolescents, ABP as well as HBP measurements appear to be superior to the conventional CBP measurements in predicting the presence of subclinical end-organ damage.

Hypertension Research (2011) 34, 640-644; doi:10.1038/hr.2011.10; published online 17 February 2011

Keywords: ambulatory blood pressure; children; home blood pressure; left ventricular hypertrophy; pulse wave velocity

\section{INTRODUCTION}

Recent evidence suggests that in the last two decades the average blood pressure (BP) in children and adolescents is rising. ${ }^{1-3}$ This change may have important implications in terms of future cardiovascular risk as increased BP levels during childhood predict hypertension in adolescence and early adulthood ${ }^{4-7}$ and are associated with the presence of target-organ damage. ${ }^{8-13}$

As it is the case in adults, the phenomena of white-coat and masked hypertension appear to be common in young individuals. ${ }^{14}$ Thus, the diagnosis of hypertension in children is dependent on accurate clinic and out of clinic BP measurements. ${ }^{15}$ Reference values for ambulatory BP (ABP) in children are available ${ }^{16,17}$ and accumulating data suggest that this method is more accurate in the diagnosis of hypertension and more closely associated with target-organ damage than the conventional clinic BP (CBP) measurements. ${ }^{18}$ On the other hand, home BP (HBP) monitoring is regarded as an easily applicable and useful adjunct to CBP for the assessment of hypertension in adults; however data in children and adolescents are limited. ${ }^{19,20}$ Only recently, reference HBP values in the pediatric population have been published but there is no evidence on their relationship with target-organ damage. ${ }^{21}$
This study was designed to compare $\mathrm{HBP}$ with $\mathrm{ABP}$ and $\mathrm{CBP}$ measurements in terms of their association with subclinical targetorgan damage in children and adolescents.

\section{METHODS}

Subjects and study design

This study enrolled children and adolescents recruited in the Arsakeion study, a school-based cross-sectional study that evaluated home and clinic BP measurements in 778 healthy children and adolescents aiming to determine the normal range of HBP in the pediatric population. ${ }^{21}$ Exclusion criteria were current or previous treatment with antihypertensive drugs, diabetes mellitus, renal, cardiac or other systemic disease, acute illness, evidence of secondary hypertension and $\mathrm{BP}$ in the range of stage 2 hypertension in two consecutive clinic visits. Subjects participating in the Arsakeion study with clinic and/or home BP $>90$ th centile were invited to participate in this study that was conducted in a University hospital-based BP Clinic. ${ }^{21}$ Children and adolescents referred to the Hypertension Center because of elevated BP were also recruited. A medical history was taken with the assistance of the participants' parents and anthropometric characteristics (weight, height and arm circumference) were recorded. The protocol was approved by the hospital scientific committee and written informed consent was obtained from all participants and/or their parents.

${ }^{1}$ Hypertension Center, Third University Department of Medicine, Sotiria Hospital, Athens, Greece; ${ }^{2}$ Division of Pediatric Cardiology, Onassis Cardiac Surgery Center, Athens, Greece; ${ }^{3}$ Cardiology Department, P and A Kyriakou Children's Hospital, Athens, Greece and ${ }^{4}$ First Department of Pediatrics, P and A Kyriakou Children's Hospital, Athens, Greece Correspondence: Professor GS Stergiou, Hypertension Center, Third University Department of Medicine, Sotiria Hospital, 152 Mesogion Avenue, Athens 11527, Greece. E-mail: gstergi@med.uoa.gr

Received 4 September 2010; revised 21 November 2010; accepted 5 December 2010; published online 17 February 2011 


\section{BP measurements}

Participants had their BP assessed in the clinic, at home and with 24-h ABP monitoring. Clinic BP was measured in one study visit by two physicians who fulfilled the British Hypertension Society Protocol criteria for agreement among observers in BP measurement. ${ }^{22}$ Triplicate BP measurements were performed after $5 \mathrm{~min}$ sitting rest and with at least $1 \mathrm{~min}$ between recordings, using standard mercury sphygmomanometers (inflatable bladder size $9 \times 18,12 \times 24$ or $15 \times 35 \mathrm{~cm}$ according to the individuals' arm circumference) and the average was used in the analysis. Clinic hypertension was defined as CBP systolic and/or diastolic $\geqslant 95$ th percentile using the existing normative data. ${ }^{23}$

Home BP was monitored for 6 routine school days within 2 weeks using automated oscillometric devices Omron 705IT (Omron Healthcare Europe BV, Hoofddorp, The Netherlands; inflatable bladder size $9 \times 16,13 \times 23$ or $15 \times 30 \mathrm{~cm}$ where appropriate), which has been validated in pediatric population. ${ }^{24}$ Participants, or their parents for younger children, were trained in the conditions of HBP measurement and the use of the electronic devices. They were instructed to take duplicate morning (0600-1000 hours) and evening (1800-2200 hours) HBP measurements after $5 \mathrm{~min}$ sitting rest and with $1 \mathrm{~min}$ interval between measurements. A form was supplied to the participants to report all their HBP values, which were also downloaded from the devices' memory through computer link. The latter values were used in the analysis. In cases of discrepancy between selfreported and downloaded HBP values, a detailed interview was conducted in order to define those that were representative of the recommended schedule. Home hypertension was defined as home systolic and/or diastolic BP $\geqslant 95$ th percentile using the normative data from the Arsakeion School study. ${ }^{21}$

ABP was monitored on a usual school day before or after the HBP monitoring period (order according to participants' preference and devices availability) using validated oscillometric devices SpaceLabs 90207 or 90217 (SpaceLabs Inc, Redmond, WA, USA, bladder size $9 \times 16,12 \times 23$ or $14 \times 30 \mathrm{~cm}$ as appropriate; measurements at 20 -min intervals for $24 \mathrm{~h}$ ). Subjects were instructed to remain still with their arm extended and relaxed during each measurement. Daytime and nighttime periods were defined according to the individual's reported sleeping times. Ambulatory hypertension was defined as average 24-h systolic and/or diastolic $\mathrm{ABP} \geqslant 95$ th percentile. ${ }^{16}$

Before each home or ambulatory BP monitoring session, the accuracy of the device was tested against a standard mercury sphygmomanometer in each individual ( $\mathrm{Y}$ connector, three successive readings) to ensure that there was no consistent difference of $>10 \mathrm{~mm} \mathrm{Hg}$ in measured BP. All clinic, home and ambulatory BP measurements were taken in the same (non-dominant) arm of each individual.

\section{Echocardiography}

M-Mode echocardiogram was performed by two observers experienced in pediatric echocardiography. Left ventricular mass (LVM) was determined from standard echocardiographic measurements according to the American Society of Echocardiography (average of three cardiac cycles) of the left ventricular enddiastolic dimension, the intraventricular septal thickness and the left ventricular posterior wall thickness and was calculated using the formula: left ventricle mass $(\mathrm{g})=0.80[1.04$ (intraventricular septal thickness+left ventricular enddiastolic dimension+left ventricular posterior wall thickness) ${ }^{3}-$ (left ventricular end-diastolic dimension) $\left.{ }^{3}\right]+0.6$ (with echocardiographic measurements in centimeters) ${ }^{25}$ LVM was corrected by height in meters at the power of 2.7 to give LVM index (LVMI). ${ }^{26}$

\section{Pulse wave analysis}

Carotid-femoral pulse-wave velocity (PWV) was measured in the supine position automatically using the Complior apparatus (Colson, Garges-lesGonesse, Paris France) as previously described. ${ }^{27}$ Its determination is based on the simultaneous recording of the pulse wave in the common carotid and femoral arteries by two transducers and is calculated as the distance separating the two transducers divided by the time delay between the onset (foot) of the two recorded waves.

\section{Statistical analysis}

Subjects with less than 12 valid HBP and/or 11 valid awake or 7 asleep ABP readings were excluded. All valid home $\mathrm{BP}$ readings were averaged to give a single number per individual. Systolic ABP readings $<50 \mathrm{~mm} \mathrm{Hg}$ or $>250 \mathrm{~mm} \mathrm{Hg}$ BP or diastolic $<30 \mathrm{~mm} \mathrm{Hg}$ or $>150 \mathrm{~mm} \mathrm{Hg}$ were excluded, as were ambulatory measurements flagged by the software of the monitors as being technically erroneous. Ambulatory readings taken $<20 \mathrm{~min}$ after the monitor had been attached to subjects were also excluded because these had been taken in the clinic.

Repeated-measures analysis of variance was used for the comparison of BP measurements obtained by different methods in the same subjects and Bonferroni's correction for multiple comparisons was applied where appropriate. Analysis of covariance was performed for between groups' comparisons when adjustment for several factors was necessary. Pearson correlations coefficients ( $r$ ) were determined for the assessment of the relationship of BP values with indices of target-organ damage and were compared using the $\mathrm{z}$-statistic. Stepwise multiple regression analysis was performed to identify which BP measurement methods best predict target-organ damage. Tolerance and variance inflation factor were used for the assessment of potential multicollinearity among the variables retained in the final regression models. Kappa statistic was applied to assess the agreement between ABP and HBP in diagnosing hypertension. Results are expressed as mean values with s.d. A probability value $P<0.05$ was considered statistically significant. Statistical analysis was performed using the Statistical Package for Social Sciences software (SPSS release 13.0; SPSS Inc., Chicago, IL, USA).

\section{RESULTS}

\section{Participants characteristics}

A total of 93 children were recruited. In six children there was a discrepancy between self-reported and downloaded HBP values, and readings for analysis were selected after an interview with the children and their parents. Five children were excluded due to inadequate number of valid HBP readings, three due to inadequate ABP readings, two due to lack of target-organ damage assessment and two due to excessive PWV and LVM values (outliers with values $>200 \%$ of the average). Finally, 81 children ( 35 aged 6-12 years and 46 aged $13-18$ years) fulfilled the inclusion criteria and were included in the analysis. Of these subjects, 76 (94\%) were assessed with PWV measurements and $54(67 \%)$ had echocardiography. Thirty children had systolic and/or diastolic CBP $\geqslant 95$ th percentile, 16 had average 24-h ABP $\geqslant 95$ th percentile and 16 had HBP $\geqslant 95$ th percentile. The main characteristics of the study participants are presented in Table 1. The average number of HBP readings was $22.8 \pm 2.5$, whereas of $24-\mathrm{h}$ ABP readings was $63.7 \pm 5.9$ (38.7 \pm 5.9 for daytime and $25 \pm 3.9$ for nighttime).

Table 1 Participants' characteristics ( $n=81$, mean \pm s.d.)

\begin{tabular}{|c|c|}
\hline Age (years) & $13 \pm 3$ \\
\hline Males (\%) & $53(65)$ \\
\hline Height $(\mathrm{cm})$ & $162.1 \pm 18$ \\
\hline Weight (kg) & $59.7 \pm 20.7$ \\
\hline Body mass index $\left(\mathrm{kg} \mathrm{m}^{-2}\right)$ & $22 \pm 4.3$ \\
\hline Clinic systolic BP $(\mathrm{mm} \mathrm{Hg})$ & $122.1 \pm 15.1$ \\
\hline Clinic diastolic BP $(\mathrm{mm} \mathrm{Hg})$ & $71 \pm 12.9$ \\
\hline Clinic heart rate (b.p.m.) & $83.4 \pm 14.7$ \\
\hline 24-h systolic BP $(\mathrm{mm} \mathrm{Hg})$ & $118.9 \pm 12$ \\
\hline 24-h diastolic BP ( $\mathrm{mm} \mathrm{Hg})$ & $66.6 \pm 6.1$ \\
\hline 24-h heart rate (b.p.m.) & $77.5 \pm 9.3$ \\
\hline Home systolic BP $(\mathrm{mm} \mathrm{Hg})$ & $121.3 \pm 11.5$ \\
\hline Home diastolic BP $(\mathrm{mm} \mathrm{Hg})$ & $69.4 \pm 6.6$ \\
\hline Home heart rate (b.p.m.) & $78.3 \pm 10.4$ \\
\hline Pulse wave velocity $\left(\mathrm{m} \mathrm{s}^{-1}\right)$ & $6.5 \pm 1.5$ \\
\hline Left ventricular mass (g) & $111.7 \pm 34.8$ \\
\hline Left ventricular mass index $\left(\mathrm{g} \mathrm{m}^{-2.7}\right)$ & $28.5 \pm 5$ \\
\hline
\end{tabular}

Abbreviation: $\mathrm{BP}$, blood pressure. 
Comparison of clinic, home and ambulatory BP

Systolic daytime ABP $(125.5 \pm 12.7 \mathrm{~mm} \mathrm{Hg})$ was higher compared with clinic $(122.1 \pm 15.1, \quad P=0.02)$ and home $(121.3 \pm 11.5$, $P<0.001$ ) BP, (analysis of variance $P=0.001$ ). Diastolic daytime

Table 2 Bivariate correlation coefficients of blood pressures and heart rates with target-organ damage

\begin{tabular}{|c|c|c|}
\hline & $\begin{array}{c}\text { Left ventricular } \\
\text { mass (g) }\end{array}$ & $\begin{array}{c}\text { Pulse wave } \\
\text { velocity }\left(m s^{-1}\right)\end{array}$ \\
\hline \multicolumn{3}{|l|}{ Systolic BP ( $\mathrm{mm} \mathrm{Hg})$} \\
\hline Clinic & $0.41^{*}$ & $0.47^{*}$ \\
\hline Home & $0.53^{*}$ & $0.50^{*}$ \\
\hline 24-h ambulatory & $0.55^{*}$ & $0.52 *$ \\
\hline Daytime ambulatory & $0.54^{*}$ & $0.50 *$ \\
\hline Nighttime ambulatory & $0.45^{*}$ & $0.48^{*}$ \\
\hline \multicolumn{3}{|l|}{ Diastolic BP (mm Hg) } \\
\hline Clinic & 0.001 & 0.15 \\
\hline Home & 0.11 & $0.28^{*}$ \\
\hline 24-h ambulatory & 0.05 & $0.30^{*}$ \\
\hline Daytime ambulatory & 0.01 & $0.31^{*}$ \\
\hline Nighttime ambulatory & -0.01 & 0.14 \\
\hline \multicolumn{3}{|l|}{ Pulse pressure $(\mathrm{mm} \mathrm{Hg})$} \\
\hline Clinic & $0.37^{*}+$ & $0.37 *$ \\
\hline Home & $0.55^{*}$ & $0.42 *$ \\
\hline 24-h ambulatory & $0.65^{*}$ & $0.47 *$ \\
\hline Daytime ambulatory & $0.64^{*}$ & $0.42 *$ \\
\hline Nighttime ambulatory & $0.58^{*}$ & $0.50^{*}$ \\
\hline \multicolumn{3}{|l|}{ Heart rate (b.p.m.) } \\
\hline Clinic & $-0.60^{*}$ & $-0.23^{*}$ \\
\hline Home & $-0.62^{*}$ & $-0.28^{*}$ \\
\hline 24-h ambulatory & $-0.67^{*}$ & $-0.27^{*}$ \\
\hline
\end{tabular}

Abbreviation: BP, blood pressure.

${ }^{*} P<0.05$

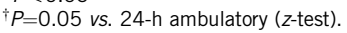

ABP $(72.7 \pm 6.7 \mathrm{~mm} \mathrm{Hg})$ also tended to be higher than clinic $(71 \pm 12.9, P=0.44)$ and was higher than home $(69.4 \pm 6.6, P<0.01)$ BP (analysis of variance $P=0.01$ ). CBP was significantly correlated $(P<0.001)$ with HBP $(r=0.67 / 0.62$, systolic/diastolic $)$, daytime ABP $(r=0.72 / 0.56)$, nighttime ABP $(0.59 / 0.49)$ and 24-h ABP $(0.70 / 0.56)$. HBP was significantly correlated $(P<0.001)$ with daytime ABP $(r=0.82 / 0.67)$, nighttime $\mathrm{ABP}(0.75 / 0.52)$ and $24-\mathrm{h} \mathrm{ABP}(0.83 / 0.66)$. Agreement between ambulatory and home BP in diagnosing hypertension was found in $85 \%$ of the participants $(\kappa=0.53)$.

\section{Relationship of BP with target-organ damage}

The associations of CBP, HBP and ABP as well as pulse pressure and heart rate with LVM and PWV are shown in Table 2. HBP and ABP showed consistently higher correlation coefficients with PWV and LVM compared with CBP, although these differences did not reach statistical significance (Table 2). Using LVMI, no significant correlations were observed with systolic CBP $(r=-0.14)$, HBP (0.09) and 24$h$ ABP (0.06). The linear associations of systolic CBP, HBP and ABP with PWV and LVM are presented in Figure 1.

Hypertensive compared with normotensive children classified on the basis of any of the tested BP measurement methods had or tended to have higher values of PWV and LVM (Table 3). Stepwise multiple regression analysis was performed with age, gender, body mass index (BMI), clinic, home and 24-h ambulatory systolic/diastolic BP and pulse pressure, clinic, home and 24-h ambulatory heart rate as independent variables, and PWV or LVM as dependent variables (Table 4). This analysis showed that PWV was best predicted by systolic HBP, whereas LVM was mainly determined by 24 -h ambulatory pulse pressure, age, 24-h heart rate and BMI. In the final models, the lowest observed tolerance was 0.57 and the highest variance inflation factor was 1.75 , which ensure the lack of multicollinearity between the used covariates.

\section{DISCUSSION}

This study assessed the relationship of different methods of BP measurements with target-organ damage in children and adolescents referred to a BP clinic. The main findings are as follows: (i) strong
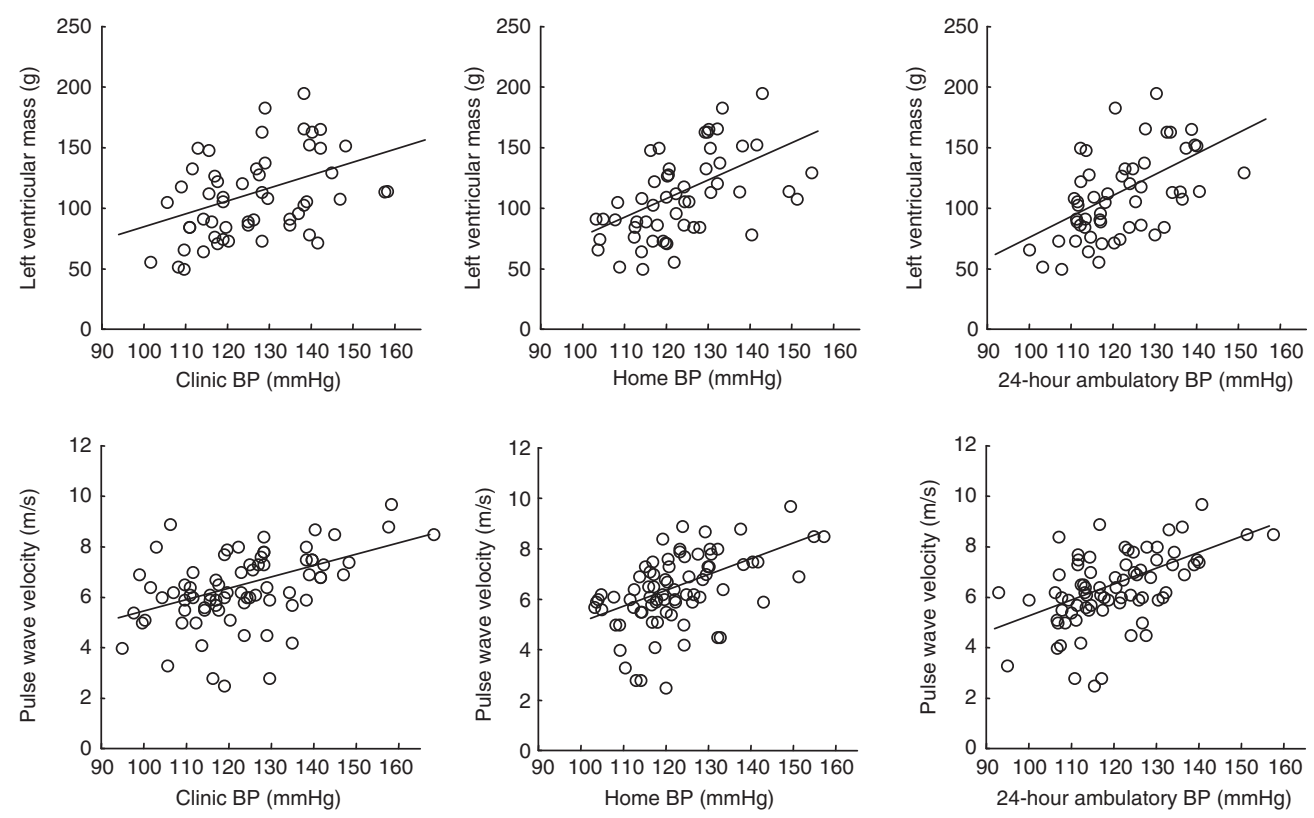

Figure 1 Correlations between different systolic blood pressure measurements and indices of target-organ damage (left ventricular mass and pulse wave velocity). 
Table 3 Target-organ damage in hypertensive compared with normotensive children classified on the basis of different blood pressure measurement methods

\begin{tabular}{|c|c|c|c|c|c|c|}
\hline Blood pressure & \multicolumn{2}{|c|}{ Normortensives } & \multicolumn{2}{|c|}{ Hypertensives } & \multicolumn{2}{|c|}{$\mathrm{P}$-value } \\
\hline \multicolumn{7}{|c|}{ Left ventricular mass (g) } \\
\hline Clinic & $n=31$ & $106.2 \pm 34.1$ & $n=23$ & $119.1 \pm 35.1$ & 0.18 & $0.82^{a}$ \\
\hline Home & $n=41$ & $104.1 \pm 31.5$ & $n=13$ & $135.5 \pm 35.2$ & 0.004 & $0.53^{a}$ \\
\hline Ambulatory & $n=41$ & $109.3 \pm 36.0$ & $n=13$ & $119.3 \pm 31.0$ & 0.37 & $0.54^{a}$ \\
\hline \multicolumn{7}{|c|}{ Pulse wave velocity $\left(\mathrm{ms}^{-1}\right)$} \\
\hline Clinic & $n=48$ & $6.1 \pm 1.4$ & $n=28$ & $7.1 \pm 1.4$ & 0.004 & $0.06^{a}$ \\
\hline Home & $n=60$ & $6.2 \pm 1.4$ & $n=16$ & $7.2 \pm 1.4$ & 0.01 & $0.29^{a}$ \\
\hline Ambulatory & $n=61$ & $6.2 \pm 1.4$ & $n=15$ & $7.4 \pm 1.2$ & 0.003 & $0.03^{a}$ \\
\hline
\end{tabular}

95th percentiles for each BP measurement method were used to define hypertension. ${ }^{a}$ Adjusted for age, gender and body mass index.

Table 4 Independent determinants of pulse wave velocity and left ventricular mass estimated by stepwise multiple linear regression

\begin{tabular}{lcc}
\hline Covariates & $\begin{array}{c}\text { Pulse wave velocity } \\
\left(\mathrm{ms}^{-1}\right)\left(R^{2}=0.22\right)\end{array}$ & $\begin{array}{c}\text { Left ventricular mass } \\
(g)\left(R^{2}=0.67\right)\end{array}$ \\
\hline Age (years) & - & $2.93 \pm 1.32^{*}$ \\
Systolic home BP $(\mathrm{mm} \mathrm{Hg})$ & $0.06 \pm 0.01^{\dagger}$ & - \\
24-h pulse pressure $(\mathrm{mm} \mathrm{Hg})$ & - & $1.21 \pm 0.41^{\dagger}$ \\
24-h heart rate & - & $-1.27 \pm 0.41^{\dagger}$ \\
Body mass index $\left(\mathrm{kg} \mathrm{m}^{-2}\right)$ & - & $1.78 \pm 0.70^{*}$ \\
\hline
\end{tabular}

Abbreviation: BP, blood pressure.

Results as $\beta \pm$ s.e. Age, gender, body mass index, clinic, home and 24-h ambulatory systolic/ diastolic BP and pulse pressure, clinic, home and 24-h ambulatory heart rate were initially

included as independent variables ( $F$-to-enter $\leqslant 0.05$, F-to-remove $\geqslant 0.10$ ).

${ }^{*} P<0.05$

$\uparrow \leqslant 0.01$

associations were found among clinic, home and ambulatory BP measurements; (ii) there was satisfactory agreement between home and ambulatory BP in diagnosing hypertension; (iii) ambulatory and home BP measurements were linearly correlated with indices of targetorgan damage and more closely than clinic BP; (iv) when reference values of clinic, home or ambulatory BP values were used, hypertensive compared with normotensive children exhibited adverse targetorgan damage parameters; (v) ambulatory and home BP, but not clinic BP were independent predictors of target-organ damage.

In agreement with previous reports in children and adolescents, awake ABP was higher than clinic and home $\mathrm{BP}^{28}$ This is in contrast to the findings in adults and is attributed at least in part to the increased level of physical activity during the day in young individuals. However, all the methods of BP measurements were highly correlated to each other and, in line with previous data, there was agreement between ambulatory and home BP in diagnosing hypertension in $85 \%$ of the study participants. ${ }^{29}$

All BP measurements were correlated with target-organ damage, that is, PWV and LVM; in this respect, however, ambulatory and home BP showed a consistent superiority compared with CBP. Moreover, in multivariate analyses only ambulatory and home BP appeared to be independent predictors of target-organ damage. The use of ABP monitoring in children and adolescents has gained great publicity in the last years and is regarded as an indispensable method for the diagnosis of pediatric hypertension. ${ }^{16,17}$ Reference ABP values for children adjusted for gender and height or age are available and increased ABP values have been associated with left ventricular hypertrophy, increased carotid intima-media thickness and impaired renal function in young individuals, in most cases to a higher degree compared with CBP.9,11-13,30 On the other hand, HBP monitoring in children and adolescents is feasible ${ }^{19}$ and reference values have been recently published. ${ }^{21}$ However, to date, HBP measurements have not been tested in regard to the presence of target-organ damage in children. This is the first study to investigate this association and to report strong correlation of HBP with LVM and PWV, to a similar degree as ABP and stronger than that of CBP. Most importantly, hypertensive compared with normotensive children classified on the basis of HBP had higher values of both LVM and PWV, whereas this difference did not reach statistical significance for LVM when ABP or CBP was used for the diagnosis of hypertension (Table 3). However, it should be noted that these differences were attenuated when adjusted for age, gender and BMI (Table 3).

Left ventricular hypertrophy is the most well established index of target-organ damage of hypertension among young individuals with prevalence among hypertensive children reported from 10 to $46 \%{ }^{18}$ However, some studies failed to reveal an independent association of casual and/or ambulatory systolic/diastolic BP with LVMI or the presence of left ventricular hypertrophy, implying that factors such as the duration of hypertension or the characteristics of the study population (age, gender, presence of obesity or other comorbidities) may have an important role. ${ }^{31-33}$ In the present study, LVM was significantly associated with systolic BP (mainly HBP and ABP and less so for CBP), nevertheless, LVMI was not significantly associated with systolic BP irrespective of the method used. This might be attributed, at least in part, to the fact that LVMI is an index corrected for body size, whereas BP (which in the pediatric population greatly varies according to age and body size) was used in the analyses unadjusted. It should be noted that in multivariate regression analysis, 24-h ambulatory pulse pressure along with BMI, age and 24-h heart rate were found to be independent predictors of LVM and accounted for a large proportion of the variance in LVM values, which confirm the results of previous reports. ${ }^{30}$

Arterial wall stiffness assessed by PWV appears to have an important role in the development of cardiovascular disease in adults. ${ }^{34}$ Despite that no true gold standard has been established in children, the available evidence points to the PWV as the most widely studied, utilized and accepted method for the assessment of the arterial stiffness. ${ }^{35}$ Interestingly, in this study PWV was highly correlated with all BP values, implying that indeed hypertension is associated with increased arterial stiffness since young age. Most importantly, in multivariate regression analysis, systolic HBP was found to best predict PWV values as compared with the other methods of BP measurements.

The findings of this study should be interpreted in light of some limitations, such as the relatively small sample size, the lack of information on the duration of the increased BP levels and the cross-sectional design of the study. However, the results of the multivariate regression analyses are reassuring for the superiority of HBP and $\mathrm{ABP}$ compared with $\mathrm{CBP}$ in the assessment of subclinical targetorgan damage in children, which is in line with similar data in adults. $^{36-38}$

In conclusion, these data suggest that in children and adolescents increased office and out-of-office BP is associated with adverse effects regarding target-organ damage at the level of the heart and the arteries. Moreover, it provides the first evidence that home BP is at least as closely correlated with target-organ damage as ambulatory BP and to a higher degree than clinic measurements. 


\section{CONFLICT OF INTEREST}

The authors declare no conflict of interest.

\section{ACKNOWLEDGEMENTS}

University of Athens grant (Kapodistrias Program 2005 and 2006, Grant No 70/4/8107). Home blood pressure monitors were provided by G Leoussis IS, Athens, Greece.

1 Muntner P, He J, Cutler JA, Wildman RP, Whelton PK. Trends in blood pressure among children and adolescents. JAMA 2004; 291: 2107-2113.

2 Din-Dzietham R, Liu Y, Bielo MV, Shamsa F. High blood pressure trends in children and adolescents in national surveys 1963 to 2002. Circulation 2007; 116: 1488-1496.

3 Kollias A, Antonodimitrakis P, Grammatikos E, Chatziantonakis N, Grammatikos EE, Stergiou GS. Trends in high blood pressure prevalence in Greek adolescents. J Hum Hypertens 2009; 23: 385-390.

4 Bao W, Threefoot SA, Srinivasan SR, Berenson GS. Essential hypertension predicted by tracking of elevated blood pressure from childhood to adulthood: the Bogalusa Heart Study. Am J Hypertens 1995; 8: 657-665.

5 Chen X, Wang Y. Tracking of blood pressure from childhood to adulthood: a systematic review and meta-regression analysis. Circulation 2008; 117: 3171-3180.

6 Manatunga AK, Jones JJ, Pratt JH. Longitudinal assessment of blood pressures in black and white children. Hypertension 1993; 22: 84-89.

7 Li Z, Snieder H, Harshfield GA, Treiber FA, Wang X. A 15-year longitudinal study on ambulatory blood pressure tracking from childhood to early adulthood. Hypertens Res 2009; 32: 404-410.

8 Belsha CW, Wells TG, McNiece KL, Seib PM, Plummer JK, Berry PL. Influence of diurnal blood pressure variations on target organ abnormalities in adolescents with mild essential hypertension. Am J Hypertens 1998; 11: 410-417.

9 Sorof JM, Cardwell G, Franco K, Portman RJ. Ambulatory blood pressure and left ventricular mass index in hypertensive children. Hypertension 2002; 39: 903-908.

10 Litwin M, Niemirska A, Sladowska J, Antoniewicz J, Daszkowska J, Wierzbicka A, Wawer ZT, Grenda R. Left ventricular hypertrophy and arterial wall thickening in children with essential hypertension. Pediatr Nephrol 2006; 21: 811-819.

11 Richey PA, Disessa TG, Hastings MC, Somes GW, Alpert BS, Jones DP. Ambulatory blood pressure and increased left ventricular mass in children at risk for hypertension. J Pediatr 2008; 152: 343-348.

12 Lande MB, Carson NL, Roy J, Meagher CC. Effects of childhood primary hypertension on carotid intima media thickness: a matched controlled study. Hypertension 2006; 48: 40-44.

13 Harshfield GA, Pulliam DA, Alpert BS. Ambulatory blood pressure and renal function in healthy children and adolescents. Am J Hypertens 1994; 7: 282-285.

14 Stergiou GS, Yiannes NJ, Rarra VC, Alamara CV. White-coat hypertension and masked hypertension in children. Blood Press Monit 2005; 10: 297-300.

15 Stergiou GS, Alamara CV, Vazeou A, Stefanidis CJ. Office and out-of-office blood pressure measurement in children and adolescents. Blood Press Monit 2004; 9: 293-296.

16 Lurbe E, Cifkova R, Cruickshank JK, Dillon MJ, Ferreira I, Invitti C, Kuznetsova T, Laurent S, Mancia G, Morales-Olivas F, Rascher W, Redon J, Schaefer F, Seeman T, Stergiou G, Wühl E, Zanchetti A. Management of high blood pressure in children and adolescents: recommendations of the European Society of Hypertension. J Hypertens 2009; 27: 1719-1742.

17 Urbina E, Alpert B, Flynn J, Hayman L, Harshfield GA, Jacobson M, Mahoney L, McCrindle B, Mietus-Snyder M, Steinberger J, Daniels S. Ambulatory blood pressure monitoring in children and adolescents: recommendations for standard assessment: a scientific statement from the American Heart Association atherosclerosis, hypertension, and obesity in Youth Committee of the council on cardiovascular disease in the young and the council for high blood pressure research. Hypertension 2008; 52 : 433-451.

18 Stabouli S, Kotsis V, Zakopoulos N. Ambulatory blood pressure monitoring and target organ damage in pediatrics. J Hypertens 2007; 25: 1979-1986.
19 Stergiou GS, Karpettas N, Kapoyiannis A, Stefanidis CJ, Vazeou A. Home blood pressure monitoring in children and adolescents: a systematic review. J Hypertens 2009; 27: 1941-1947.

20 Stergiou GS, Nasothimiou EG, Giovas PP, Rarra VC. Long-term reproducibility of home vs. office blood pressure in children and adolescents: the Arsakeion school study. Hypertens Res 2009; 32: 311-315.

21 Stergiou GS, Yiannes NG, Rarra VC, Panagiotakos DB. Home blood pressure normalcy in children and adolescents: the Arsakeion School study. J Hypertens 2007; 25: 1375-1379.

22 O'Brien E, Petrie J, Littler W, de Swiet M, Padfield PL, Altman DG, Bland M, Coats A, Atkins N. An outline of the revised British Hypertension Society protocol for the evaluation of blood pressure measuring devices. J Hypertens 1993; 11: 677-679.

23 National High Blood Pressure Education Program Working Group on High Blood Pressure in Children Adolescents. The fourth report on the diagnosis, evaluation, and treatment of high blood pressure in children and adolescents. Pediatrics 2004; 114: 555-576.

24 Stergiou GS, Yiannes NG, Rarra VC. Validation of the Omron 705 IT oscillometric device for home blood pressure measurement in children and adolescents: the Arsakion School Study. Blood Press Monit 2006; 11: 229-234.

25 Devereux RB, Alonso DR, Lutas EM, Gottlieb GJ, Campo E, Sachs I, Reichek N. Echocardiographic assessment of left ventricular hypertrophy: comparison to necropsy findings. Am J Cardiol 1986; 57: 450-458.

26 de Simone G, Daniels SR, Devereux RB, Meyer RA, Roman MJ, de Divitiis O, Alderman $\mathrm{MH}$. Left ventricular mass and body size in normotensive children and adults: assessment of allometric relations and impact of overweight. J Am Coll Cardiol 1992; 20: 1251-1260.

27 Protogerou A, Blacher J, Stergiou GS, Achimastos A, Safar ME. Blood pressure response under chronic antihypertensive drug therapy: the role of aortic stiffness in the REASON (Preterax in Regression of Arterial Stiffness in a Controlled Double-Blind) study. J Am Coll Cardiol 2009; 53: 445-451.

28 Stergiou GS, Rarra VC, Yiannes NG. Changing relationship between home and office blood pressure with increasing age in children: the Arsakeion School study. Am J Hypertens 2008; 21: 41-46.

29 Stergiou GS, Nasothimiou E, Giovas P, Kapoyiannis A, Vazeou A. Diagnosis of hypertension in children and adolescents based on home versus ambulatory blood pressure monitoring. J Hypertens 2008; 26: 1556-1562.

30 Stabouli S, Kotsis V, Karagianni C, Toumanidis S, Constantopoulos A, Zakopoulos N. 24-h pulse pressure predicts left ventricular mass index in children and adolescents. $J$ Hypertens 2007; 25(Suppl 2): S297-S299.

31 Brady TM, Fivush B, Flynn JT, Parekh R. Ability of blood pressure to predict left ventricular hypertrophy in children with primary hypertension. J Pediatr 2008; 152 : 73-78, $78 \mathrm{e} 1$.

32 Matteucci MC, Wuhl E, Picca S, Mastrostefano A, Rinelli G, Romano C, Rizzoni G, Mehls O, Schaefer F, ESCAPE Trial Group. Left ventricular geometry in children with mild to moderate chronic renal insufficiency. J Am Soc Nephrol 2006; 17: 218-226.

33 Daniels SR, Loggie JM, Khoury P, Kimball TR. Left ventricular geometry and severe left ventricular hypertrophy in children and adolescents with essential hypertension. Circulation 1998; 97: 1907-1911.

34 Laurent S, Boutouyrie P, Asmar R, Gautier I, Laloux B, Guize L, Ducimetiere P, Benetos A. Aortic stiffness is an independent predictor of all-cause and cardiovascular mortality in hypertensive patients. Hypertension 2001; 37: 1236-1241.

35 Urbina EM, Williams RV, Alpert BS, Collins RT, Daniels SR, Hayman L, Jacobson M, Mahoney L, Mietus-Snyder M, Rocchini A, Steinberger J, McCrindle B. Noninvasive assessment of subclinical atherosclerosis in children and adolescents: recommendations for standard assessment for clinical research: a scientific statement from the American Heart Association. Hypertension 2009; 54: 919-950.

36 Stergiou GS, Argyraki KK, Moyssakis I, Mastorantonakis SE, Achimastos AD, Karamanos VG, Roussias LG. Home blood pressure is as reliable as ambulatory blood pressure in predicting target-organ damage in hypertension. Am J Hypertens 2007; 20: 616-621.

37 Shimbo D, Pickering TG, Spruill TM, Abraham D, Schwartz JE, Gerin W. Relative utility of home, ambulatory, and office blood pressures in the prediction of end-organ damage. Am J Hypertens 2007; 20: 476-482.

38 Jula A, Puukka P, Karanko H. Multiple clinic and home blood pressure measurements versus ambulatory blood pressure monitoring. Hypertension 1999; 34: 261-266. 